\title{
DESAFIOS DA GESTÃO ESCOLAR: CONSTRUÇÃO COLETIVA E PARTICIPATIVA NA QUALIDADE EDUCACIONAL
}

\author{
ARTIGO ORIGINAL \\ BUENO, Sabrina ${ }^{1}$ \\ BORLINA, Hellen Cristine ${ }^{2}$
}

BUENO, Sabrina. BORLINA, Hellen Cristine. Desafios da gestão escolar: Construção coletiva e participativa na qualidade educacional. Revista Científica Multidisciplinar Núcleo do Conhecimento. Ano 05, Ed. 09, Vol. 04, pp. 131-140. Setembro de 2020. ISSN: 2448-0959, Link de acesso: https://www.nucleodoconhecimento.com.br/educacao/construcao-coletiva

\section{RESUMO}

A importância de termos uma gestão escolar participativa, democrática e coletiva só vem aumentando, buscando constantemente transformar o trabalho em uma parceria, integrando todos os membros envolvidos na instituição, e a comunidade na qual está inserida. Neste ponto de vista, a gestão escolar apresenta um novo modelo voltado para uma perspectiva cidadã, onde as concepções e práticas interativas, dialógicas, democráticas e participativas ganham espaço à medida que proporcionam o direito de "aprender a aprender", a construírem saberes de maneira justa e criativa, e propicia os educandos a serem sujeitos de seus conhecimentos. Acredita-se ser de suma importância a participação de todos os membros envolvidos na escola, tanto dos

${ }^{1}$ Graduada em Pedagogia. Pós Graduada em Gestão Escolar. Pós Graduada em Educação Infantil. Pós Graduada em Administração, supervisão, orientação e inspeção escolar Escolar.

${ }^{2}$ Graduada em Pedagogia. Pós Graduada em Gestão Escolar. Pós Graduada em Educação Infantil. Pós Graduada em Administração, supervisão, orientação e inspeção escolar Escolar. 
professores, quanto da equipe diretiva, funcionários, pais e toda a comunidade escolar, buscando sempre a democratização na tomada de decisões, pois através destas, torna-se possível alcançar os objetivos comuns com uma colaboração mais ampla, participativa e coletiva, com maiores possibilidades de obter êxito naquilo que se almeja dentro da instituição de ensino. Desta forma, este artigo é uma revisão de bibliografia que aborda pensamentos e ideias de autores, bem como citações diretas e indiretas, retiradas de livros e artigos científicos. Como objetivo principal foi encontrar e descrever os desafios da gestão escolar, este trabalho nos afirma que teorias supostamente concretas de exercício pleno da democracia buscam a participação coletiva e colaborativa de todos e, dentro da escola, esta participação permite que a educação proposta, melhore notavelmente.

Palavras-chaves: Gestão democrática, qualidade educacional, participação coletiva.

\section{INTRODUÇÃO}

Muito se tem discutido a respeito da temática educacional perante a administração escolar, para tanto vem se buscando diversas alternativas que possam efetivar uma gestão democrática participativa e coletiva, implantando novas posturas em relação aos gestores e todos os envolvidos na comunidade escolar.

Diante do exposto busca-se como objetivo geral efetivar uma gestão democrática com a participação de todos os segmentos da comunidade escolar, para que dessa forma consigamos construir espaços dinâmicos, através da diversidade das várias formas de entender a escola.

Quando pensamos em um novo modelo de escola democrática, coletiva e participativa, estamos buscando formas para que os gestores e docentes consigam proporcionar um espaço de interação de saberes em prol de uma aprendizagem significativa do aluno, e somente teremos sucesso se fizermos este trabalho coletivamente, ou seja, se construirmos mediações capazes de garantir uma educação coerente, responsável e transformadora, onde todos os segmentos 
envolvidos, juntos consigam tomar decisões que visem um objetivo comum. (LÜCK, 2005)

Para tanto, faz-se necessário que a equipe diretiva, sob a responsabilidade de seu gestor assuma uma postura de compromisso com a democratização escolar por meio de ações e objetivos concretos, pois no contexto atual a escola acaba por se distanciar do sentido real de democracia.

Existem inúmeros desafios em busca de uma gestão democrática coletiva, e participativa, onde estes são lançados a todos os profissionais envolvidos na educação, com o desejo de renovar as práticas educativas. Sabemos o quanto a mesma é complexa, pois toda mudança requer o repensar da prática pedagógica e dos envolvidos, a compreensão reflexiva e crítica sobre as discussões que norteiam a democratização da gestão escolar.

Conforme Paro (2006), o autor cita que não é possível que haja democracia plena se não existirem pessoas democráticas. Desta forma, buscou-se um estudo mais aprofundado e aprimorado referente a importância de existir uma gestão democrática, participativa e coletiva, sendo que, é através dela que ocorrerão as mudanças necessárias para que seja alcançado um ensino de qualidade na perspectiva de formar cidadãos democráticos, livres, participativos e conscientes.

Uma das preocupações relevantes do País é desenvolver estratégias de políticas educativas eficazes que permitam enfrentar com êxito os desafios de melhorar a qualidade e igualdade da educação.

\section{CONSTRUÇÃO DA GESTÃO DEMOCRÁTICA}

O repensar da estrutura de poder na escola, implica com a gestão democrática, tentase com isso então, anular diversos fatores negativos que possam impedir a escola de ser um âmbito mais acolhedor e social, diante disso, a democracia nas escolas tem se tornado motivo de reflexões, debates frequentes na área da educação, a fim de dar 
continuidade a um princípio posto constitucionalmente e reposto na Lei de Diretrizes e Bases da Educação Nacional.

Conforme apontado por Lück (2000, p.11)

Gestão escolar constitui uma dimensão e um enfoque de atuação que objetiva promover a organização, a mobilização e a articulação de todas as condições materiais e humanas necessárias para garantir o avanço dos processos sócio educacionais dos estabelecimentos de ensino orientadas para a promoção efetiva da aprendizagem pelos alunos, de modo a torná-los capazes de enfrentar adequadamente os desafios da sociedade globalizada e da economia centrada no conhecimento.

Conforme estabelece a Constituição de 1988 no seu (Artigo 206), igualmente na LDBEN № 9394/96 Leis de Diretrizes e Bases da Educação Nacional. Portanto, se faz de suma importância que sejam superadas as formas tradicionais de gestão escolar e organização, que sejam adotadas formas criativas, alternativas, de forma que os objetivos políticos e sociais dos alunos, professores e comunidade escolar envolvidos sejam contemplados com projetos e estratégias compatíveis para o desenvolvimento das funções operativas.

Este é um enfoque que, se adotado, exige que se abandone o modelo arcaico, antigo e fundado na cobrança. É preciso que o gestor tenha um novo perfil, com especial atenção às diversas demandas sociais que surgem, é essencial que tenha, também, novos conhecimento e habilidades para que possa dar conta dessa educação que é responsabilidade de todos. O envolvimento de professores, equipe técnico-pedagógica, funcionários, alunos, pais e comunidade, devem formar um jeito diferente de compreender o papel da escola e sua gestão. Neste modelo, o trabalho deve ser entendido como prático social e orientador da ação de gestão realizada na organização de ensino. (LÜCK 2000, p. 12)

De acordo com Gadotti (2001, p. 23)

De nada adiantaria uma Lei de Gestão Democrática do Ensino Público que concede autonomia pedagógica, administrativa e financeira às escolas, se o gestor, professores, alunos, e demais atores do processo desconhecem o significado político da autonomia. 
Para o autor citado acima, o exercício desta autonomia é uma construção individual, contínua e coletiva. Entende-se por autonomia da escola a capacidade de realização e elaboração de um projeto educativo próprio em benefício dos alunos com a participação de todos os integrantes do processo educativo. A autonomia da escola é um exercício de democratização de um espaço público, a função deste, é delegar ao diretor e aos demais agentes pedagógicos a possibilidade de dar respostas aos cidadãos a quem servem em vez de encaminhá-los para órgãos centrais distantes onde é desconhecido e, muitas vezes, sequer atendido.

O objetivo da autonomia é o fortalecimento da escola enquanto meio e a busca da qualidade com equidade enquanto meta. A autonomia coloca na escola a responsabilidade de prestar contas do que faz ou deixa de fazer sem repassar para outro setor essa tarefa e, ao aproximar família e escola, permite uma participação realmente efetiva da comunidade, o que a caracteriza como uma categoria eminentemente democrática.

Libâneo (2007, p. 308) afirma que

Na maior parte das vezes, a realidade das escolas ainda é de isolamento do professor. Sua responsabilidade começa e termina em sala de aula. A mudança dessa situação pode ocorrer pela adoção de práticas participativas, em que os professores aprendam nas situações de trabalho, compartilhem com os colegas, conhecimentos, metodologias e dificuldades, discutam e tomem decisões sobre o projeto pedagógico curricular, sobre o currículo, sobre as relações sociais internas, sobre as práticas de avaliação.

O que torna a escola democrática e participativa favorecendo ao um ensino de qualidade, aprendizagem e reflexivo, é a participação de todos os membros envolvidos na comunidade escolar, estando todos conscientes que cada um possui individualmente responsabilidades e participação ativa em um trabalho coletivo.

Lück (2005, p. 23) destaca que:

O conceito de gestão está associado à mobilização de talentos e esforços coletivamente organizados, à ação construtiva conjunta de 
seus componentes, pelo trabalho associado, mediante a reciprocidade que cria um "todo" orientado por uma vontade coletiva.

Desse modo, a escola entende a Gestão Democrática como uma forma de reestruturar seus princípios e fazer com que o processo educacional avance da melhor maneira possível proporcionando um ensino de qualidade com um planejamento participativo.

\section{PROJETO POLÍTICO PEDAGÓGICO}

O projeto político pedagógico se define como uma ferramenta importante para a implantação dessa perspectiva democrática na gestão escolar, já que sua instituição se estrutura a partir da inter-relação de professores, pais, alunos, equipe pedagógica e gestor, consistindo, assim, em um retrato fiel da administração participativa.

De acordo com Libâneo (2008), deve ser consolidado em documento, o detalhamento das ações do processo educativo a ser desenvolvido nas escolas, juntamente com os objetivos e diretrizes. Esse documento deve expressar a síntese das exigências legais, sociais, os propósitos e as expectativas do sistema de ensino da comunidade escolar.

Logo, esse mecanismo não se confunde com o papel da gestão escolar, muito menos pode substituir a formação organizacional da escola, mas serve apenas de roteiro para as ações, supõe e determina os parâmetros políticos e pedagógicos para o decurso educacional. Portanto, a administração executa as ações contempladas no projeto, pressupondo, nesse ínterim, que o projeto é uma ferramenta dessa administração. (LIBÂNEO, 2008)

O projeto político pedagógico é indispensável para a preparação de uma proposta respaldada nos processos democráticos. De acordo com a LDB 9.394/96 a proposta deve ser constituída com a participação de todos os profissionais de educação. Com base nisso, o dispositivo legal destaca a atribuição da escola e a função de todos os envolvidos para edificação de propostas educacionais delineadas com os projetos 
nacionais, os parâmetros estaduais e municipais aptos, simultaneamente, a considerar a realidade particular de cada estabelecimento educacional.

Citamos as palavras de Freire (1996, p. 77) "o mundo não é. O mundo está sendo. Não sou apenas objeto da História, mas sou sujeito igualmente. Caminho para a inserção, que implica decisão, escolha, intervenção na realidade".

Dessa forma é preciso que se estabeleça uma comunicação dialógica entre todos os participantes do processo no contorno do projeto político pedagógico e apresentar consequências favoráveis, bem como servir de fortalecimento para a gestão democrática escolar, é imprescindível que se faça uma análise pormenorizada e fiel do papel social do ensino e da escola que se fundamenta na preparação do cidadão para sua inserção na sociedade, na qual viverá como cidadão e como profissional de alguma área da atividade humana. (MORRETO, 2005)

É, através da sua existência, que a escola registra sua história, pois, é conhecido como um conjunto de diretrizes e estratégias que expressam e orientam a prática político pedagógica de uma escola.

O papel da comunidade escolar não é substituir o Estado, libertá-los de suas atribuições constitucionais, postar-se sobre sua tutela, mas se organizar de maneira competente para fazê-lo funcionar. Surge daí a necessidade da cidadania que vai determinar a qualidade do Estado. Nesse sentido, comunidade não é apenas um LOCUS geográfico espacial, mas uma categoria da realidade social, de intervenção social nesta realidade, assim como o abandono da postura, até então predominante na cultura, que é a de esperar pela ação do Estado como uma obrigação, e criticá-lo pelo não comprimento ou pela omissão (FERREIRA, 2005, p.32)

A partir do exposto, pode-se elencar alguns aspectos norteadores para a organização do projeto político pedagógico de uma escola e, organizar o trabalho pedagógico.

De acordo com Morreto (2005), o Projeto Político Pedagógico é criado de uma intencionalidade declarada, isso significa que ele é criado com o objetivo de assumir categorias de análise, uma ou mais, é capazes de auxiliar na compreensão sobre a 
realidade; não é espontânea, embora, possa ocorrer, respeitando o rítmo mais ou menos certo de sua origem, a instituição.

Desta mesma forma, o clima democrático que se faz necessário adaptar, acelera o processo educativo e esse, alimenta a experiência de cidadania, fundamental para superar o individualismo e autoritarismo presente na sociedade e em muitas instituições escolares.

O projeto político-pedagógico tem o desafio de propiciar uma qualidade educacional para todos. Atualmente, apenas uma parcela privilegiada da população (aquela que tem direito aos bens tanto matérias quanto simbólicas) detém esta forma de educação. Salientamos que a melhoria do ensino deve ser qualitativa e não quantitativa, como tanto divulga os órgãos governamentais. (VEIGA, 1988, p.14)

\section{O MEIO ESCOLAR E A IMPORTÂNCIA DO PROFESSOR NA CONSTRUÇÃO DA QUALIDADE EDUCACIONAL}

O autor Pérez Gomes (2000) cita que a função que o professor possui é de buscar a atenção e compreensão no processo de construção do conhecimento, de tal forma, o professor também precisa ser o facilitador, esse processo se dará somente pela interação compartilhada. Os conteúdos devem ser transformados, provocando a reflexão para o processo e ação educativa, não sendo a relação aluno versos professor afetada pelos pensamentos e ideias que um tem do outro e, até mesmo, as concepções que um têm para com o outro.

Segundo Libâneo (2004) a proposta de uma gestão democrática na educação é uma batalha travada desde muito tempo por educadores que visavam romper os parâmetros tradicionais de administração pautados no autoritarismo.

Chalita (2001, p.12)

A educação não pode ser vista como um depósito de informações. Há muitas maneiras de transmitir o conhecimento, mas o ato de educar só pode ser feito com afeto, esta ação só pode se concretiza com amor. Percebe-se que há uma grande diferença entre transmitir o conhecimento e educar. A diferença de educar seres humanos que se 
encontram nas primeiras etapas da vida é uma tarefa para os docentes que se preocupam na formação global do educando e não apenas na formação parcial, obtida em sala de aula. As demonstrações de carinho, bem como a afetividade nas palavras ditas pelo professor, resultarão no auxílio e conforto para o aluno, quando este necessitar acomodar as informações recebidas, sem que haja repulsão ou aversão ao conteúdo apresentado, ou até mesmo ao próprio ato de aprender algo novo.

De acordo com Libâneo (2004, p.41)

O professor que é um mediador possibilita o acesso do aluno aos diferentes tipos de saber e de saber-fazer e também às diferentes habilidades intelectuais, atitudes e valores morais. Numa perspectiva de democratização das relações, as escolas que possuem uma preocupação com bom desempenho de seus profissionais e ou/ em torno das metas propostas no caso ora em estudo do desempenho de seus alunos, tornará suas metodologias e estratégias mais eficientes e eficazes.

O principal fator de um meio escolar estimulante é o professor, talvez esteja aí um sério fator comprometedor da eficácia da escola pública democrática, participativa e com qualidade educacional, pois, o professor também carece de estimulação. As condições do êxito do trabalho escolar supõem o professor com uma formação científica de alto nível, formação que inclua também uma clara compreensão dos mecanismos do insucesso escolar. (LIBÂNIO, 1990)

Quando pensamos em qualidade educacional a contribuição da escola é de suma importância, pois é o lugar do ensino e difusão do conhecimento, é instrumento para o acesso das camadas populares ao saber elaborar. O ensino como mediação técnica deve proporcionar a todos uma formação cultural e científica de alto nível promovendo a formação da personalidade social em face de uma nova cultura. (LIBÂNIO, 1990)

\section{CONCLUSÃO}

Atualmente, tem sido muito questionado sobre a gestão escolar, principalmente nas escolas da rede pública, que têm por trás, o poder governamental e suas atribuições, seja Municipal, Estadual ou Federal. 
A gestão democrática e participativa no âmbito escolar constitui-se numa prática que deve priorizar o desenvolvimento integrado de todos os agentes envolvidos no processo pedagógico. Democratizar a escola representa um trabalho sério, que envolve o compromisso de todos os envolvidos direta ou indiretamente no processo da educação. Gestores ou diretores, administradores e professores, alunos e pais, todos são responsáveis por tudo que acontece na escola, seja na área pedagógica ou no setor administrativo.

Seria incoerente atualmente no Brasil, que vem lutando por resgatar o valor dos princípios democráticos, insistir em repetir os modelos de uma educação sólida e tradicionalista na reprodução de valores ditatoriais.

Compreendemos que uma gestão escolar democrática deve ter por finalidade promover a redistribuição de responsabilidades, com a participação e o trabalho em equipe, onde juntos, consigam decidir sobre as ações que serão desenvolvidas, analisando as situações e promovendo o confronto de ideias, procurando assim ter o êxito da organização escolar através de uma atuação consciente que venha a favorecer um ensino de qualidade, em busca na formação de cidadãos críticos, e não meros recebedores de informações.

Este trabalho nos afirma que teorias supostamente concretas de exercício pleno da democracia buscam a participação coletiva e colaborativa de todos, e, dentro da escola, esta participação permite que a educação proposta, melhore notavelmente. Este estudo não se esgota aqui e muito menos pretende ser conclusivo, mas, sugere que constantemente seja feita uma reflexão a respeito das práticas de gestão democrática e sua importância para a educação.

\section{REFERENCIAS}

BASTOS, João Baptista. Gestão Democrática. 4ª Ed. Rio de Janeiro DP\&A: SEPE, 2005. 
BRASIL, Constituição (1988). Constituição da República Federativa do Brasil. São Paulo: Saraiva 2006.

CHALITA, Gabriel. Educação: a solução está no afeto. São Paulo: Gente, 2001

FREIRE, Paulo. Pedagogia da autonomia: Saberes necessários à prática educativa. São Paulo: Paz e Terra, 1996.

FREITAS, Katia Siqueira. A escola participativa: O trabalho do gestor escolar, Rio de Janeiro, vozes, 2005.

FREITAS, Katia Siqueira. Liderança em gestão educacional: Buscando caminhos para a escola efetiva, Salvador/UFBA, 2005.

GADOTTI, Moacir. Concepção dialética da educação: um estudo introdutório. São Paulo: Cortez, 2001.

GADOTTI, Moacir. Escola Cidadã. São Paulo: Cortez, 1993.

A gestão participativa na escola. 2. ed. Vozes: Petrópolis, 2006.

GÓMEZ, A. I. P. A aprendizagem escolar: da didática operatória à reconstrução da cultura na sala de aula. In: SACRISTÁN, J. G.; PÉREZ GÓMEZ, A. I. Compreender e transformar o ensino. 4. Ed. Porto Alegre: Artmed, 2000.

LIBÂNEO, J. C. Didática. São Paulo: Cortez, 1994.

LIBÂNEO, José Carlos. Democratização da Escola Pública. São Paulo: Loyola, 1990.

LIBANEO, José Carlos. Organização e gestão da escola: teoria e prática. 5. Ed. rev. ampl. Goiânia: Alternativa, 2004.

LIBÂNEO, José Carlos. Organização e gestão da escola: teoria e prática. $6^{\mathrm{a}}$ edição, São Paulo, Heccus Editora 2013. 
LÜCK, H. A escola participativa: o trabalho do gestor escolar. Petrópolis, Rio de Janeiro, Editora Vozes, 2005.

PARO Vitor Henrique. Gestão democrática da escola pública. 3 ed. São Paulo: Ática, 2000.

RODRIGUES, Neidson. Da mistificação da escola a escola necessária. 11 ed. São Paulo: Cortez, 2003.

SILVA, Jair Militão. Autonomia da escola pública. São Paulo: Papirus, 1996

VEIGA, I. P. A. (Org.) Projeto Político Pedagógico: Uma Construção Possível. Campinas, SP: Papirus, 1997.

VEIGA, Ilmar Passos Alencastro. Projeto político-pedagógico da escola: uma construção coletiva, in Projeto político-pedagógico da escola: uma construção possível. Ed Cortez, 1998.

Enviado: Julho, 2020.

Aprovado: Setembro, 2020. 